\section{He'll hold 'til Euston}

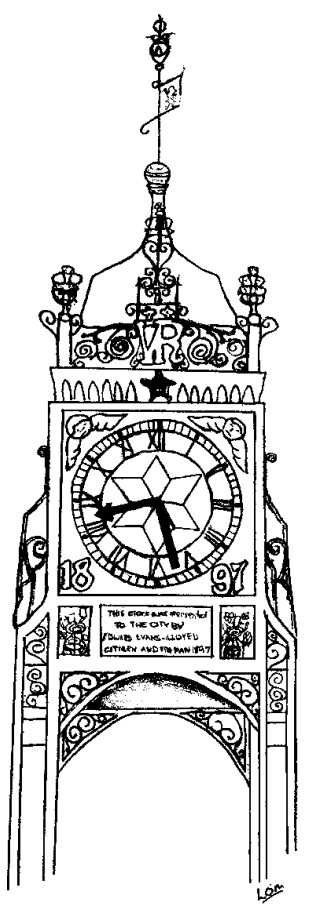

EASTGATE CLOCK, CHESTER
"Is there a doctor on the train?" No! Come here now, you must be jokin'. Haven't I just done the baby on the ferry. They can't be serious! "I repeat, if there's a doctor on the train, would they kindly make themselves known to the nearest steward or go up to the First Class area."

There I am, in Second Class, with two nurses, Mary and Clare, and the pair of them saying"Go on Colm. They are looking for a doctor."

At this stage, I have already broken out into a nervous sweat, as I weigh up the chances of there being an acute case of syphilis, gonorrhoea, or warts up in First Class, needing my urgent attention.

Anyway, up I go into the hallowed halls of First Class. There's a young man there in a grey suit, with matching grey skin, looking decidedly unwell. However, to my enormous relief there was a handsome, tanned, immaculately dressed, confident man in full control of the situation dealing with him. I felt I should at least explain my presence and leave him to get on with it, so I tentatively said "Hello, I'm Dr O'Mahony, and you appear to have everything sorted." He smiled and turned to me, and said "Hello, I'm the coach from ... Rugby Club, please take over," and off he went. I was tempted to say "Come back, I'm a venereologist. Let's give the patient a choice as to who he'd sooner be seen by."

With trepidation, I had a look at the young man and a bit of superficial palpation suggested to me that he probably had appendicitis. I didn't think First Class Virgin Rail was the ideal location to do a rectal, but I'm sure the Medical Protection Society would understand. I did, however, call for a large bucket and a big towel. When asked by the startled steward what these were for, I explained that there was a serious risk of the interior of this First Class carriage being redecorated with diced carrot at any moment, and the towel was for me, as this was my only suit, and there was a long day ahead in London. It turned out to be a wise move.

Now, what were we to do with this young man and his appendix? Stop the train, pull into some hamlet, wait for an ambulance, cause massive disruption to the whole North West Railway line at only 9 am on a Friday morning? London was only 20 minutes away, and I confidently proclaimed "He'll hold 'til Euston. Have an ambulance waiting there, and I'll stay with him until then." So that's what happened.

The chap in the red waistcoat from Virgin Rail was quite relieved when the young man was transferred into the ambulance and, boy, so was I! He then said to me "Dr Armani (!), we are very grateful and we'll definitely be in touch." I said "Here, give me that pen, and I will carefully write down my name and address," thinking I might be the proud recipient of a Virgin Rail upgrade to First Class for my next AGUM trip.

They did get in touch. I got a letter about two months later, saying, "Dear Dr O'Mally (!), Thank you for your complaint, which we are investigating." I couldn't believe it. I just had to write back. This time, using "management speak." I patiently explained that I hadn't complained; I had used evidence based medicine, clinical governance, and audit to arrive at a risk management strategy that encompassed all the variables, allowing a win-win situation to develop for the benefit of the patient, Virgin Rail, and myself—-that is, "He'll hold 'til Euston." My letter obviously received detailed consideration, as I got another standard letter back, thanking me for my comments, and that "customer feedback is always appreciated, and helps to improve the service." I ask you! Customer feedback!

Is there a lesson to be learnt from all this? YES! My staff say-never travel with Dr O'Mahony.

Colm O'Mahony, Countess of Chester Hospital NHS Trust, Chester CH2 1UL, UK 